\title{
FOCAL SEGMENTAL GLOMERULOSCLEROSIS ASSOCLTED WITH MYELOPROLIFERATIVE DISORDER
}

\section{By \\ Fatin Sayes(1) Saad Shohaib(2), Abdullah Almalki(3)}

\author{
From \\ 1) Department of Hematology, King Abdulaziz University Hospital, Jeddah
}

2) Department of Medicine, Nephrology, King Abdulaziz University Hospital, Jeddah

3) Department of Medicine, National Guard Hospital, Jeddah

\begin{abstract}
KEYWORDS : Polycythemia vera, nephrotic syndrome

Polycythemia vera is a clonal disorder originating in a pluripotent hematopoietic stem cells.
\end{abstract}

Nephrotic syndrome is a clinical complex characterized by a number of renal and extra renal features, the most prominent of which are proteinuria (>3.5 g per day), hypoalbuminemia, oedema, hyperlipidemia and hypercoagulability. The target defect is altered permeability of the glomerular filtration barrier for protein leading to glomerular proteinuria. Primary renal disorders account for most of the cases. Common systemic disease associated with nephrotic syndrome includes diabetes mellitus, systemic lupus erythematosus, amyloidosis and multiple myeloma. We describe a case of nephrotic syndrome due to focal segmental glomerulosclerosis (FSGS) associated with myeloproliferative disease (MPD).

The association between MPD, including polycythemia vera and nephrotic syndrome has been described in case reports and case series. Secondary causes for nephrotic syndrome were excluded. We speculate that the casual relationship between the two diseases is very likely. Possible causes postulated in literature are discussed. However, the exact pathophysiologic basis remain to be confirmed.

\section{INTRODUCTION}

Polycythemia vera (PV) is a myeMANSOURA MEDICAL JOURNAL 
loproliferative disorder of clonal origin with the primary defect residing in a multipotenent hematopoietic progenitor cells (Adamson et al, 1976)(1). It is characterized by over production of erythrocytes (Turk et al, 1959; Najean et al, 1981) as well as myeloid and megakaryocytic proliferation (Turk, 1904)(2).

The peak age of onset is $50-75$ years, men are affected somewhat more commonly than women $(3,4)$. The diagnosis of $\mathrm{PV}$ is made after ruling out the causes of secondary erythrocytosis, and fulfillment of the polycythemia rubra vera study group (PVSG) criteria $(5,6)$ The clinical course in $\mathrm{PV}$ is marked by significant risk of thrombotic complications and a variable incidence of transformation to myeloid metaplasia with myelofibrosis (MMM) or acute myeloid leukemia (AML). Approximately $10-15 \%$ of patients will develop post polycythemia MMM, after an average of ten years from diagnosis. The incidence rises to over $30 \%$ in patients surviving to the $20^{\text {th }}$ year (7). Although several report have presented cases of erythrocytosis with concomitant renal glomerular disease $(8,9,10,12)$, there are few reports regarding the simultaneous occurrence of PV and glomerular disease only a few reports previously presented PV associated with diffuse mesangial proliferative glomerulonephritis (GN) (13), Henoch Schonlein purpura nephritis (HSP) $(14)$, focal segmental glomerulosclerosis (FSGS) $(15,16)$ and IgA nephropathy $(\lg A-N)(17,18)$. We describe a 51 year-old male patients with post polycythemia vera, MMM and nephrotic syndrome due to FSGS. Secondary causes for nephrotic syndrome were excluded. The possible pathogenesis for this simultaneous occurrence is discussed with review of the literature.

\section{CASE REPORT}

A 51 year-old Yemeni man presented to our hospital with chief complaints of lower limbs swelling with increasing left hypochondrial swelling. $\mathrm{He}$ is known to have polycythemia vera diagnosed in other hospital for 10 years, maintained on allopurinol and aspirin. There is a history of dyspnea on exertion. Orthopnea and hypermetabolic symptoms in the form of sweating and fever for 3 months. $\mathrm{He}$ denied any symptorns suggestive of hyperviscosity and had no thrombotic complications. He had several "as indicated ' phlebotomy sessions for high hematocrit level of which the

Vol. 35, No. 3 \& 4 July., \& Oct, 2004 
last session was 4 years ago. $\mathrm{He}$ is known hypertensive for 10 years on atenolol $100 \mathrm{mg}$ daily and captopril 50 $\mathrm{mg}$ twice daily. His older sister suffers from the same hematological disease and there was positive family history of diabetes mellitus, hypertension, ischemic heart disease and cerebrovascular disease. No history of smoking was taken. The physical examination revealed elevated blood pressure $(150 / 100) \mathrm{mmHg}$ otherwise stable vital signs. He has signs of volume overload with raised JVP and bilateral lower limb pitting edema. Abdominal examination revealed hepatomegaly with massive splenomegaly. There was no evidence of cutaneous or neurological abnormalities. Laboratory findings disclosed the following: white blood cell (WBC) count $32.0 \times 10^{9} / \mathrm{L}\left(32,000 / \mathrm{mm}^{3}\right)$ red blood cell (RBC) count $5.5 \times 10^{12} / \mathrm{L}(5.600 /$ $000 \mathrm{~mm}^{3}$ ), hematocrit $56.4 \%$, hemoglobin $17.5 \mathrm{~g} / \mathrm{dL}$ and platelets $651 \times 10^{9}$ / $\mathrm{L}\left(651,000 \cdot \mathrm{mm}^{3}\right)$. The RBCs were normochromic and normocytic. Hemoglobin level spontareouslv and gradually decreased to $11 \mathrm{~g} / \mathrm{dL}$ on subsequent outpatient visits over 4 months.

Peripheral blood film revealed elevated count with modest basophilia, infrequent teardrops and immature myeloid forms with no abnormal cells. Urin analysis demonstrated proteinuria, hematuria and red cell casts. LDH 958 U/L (100-190), uric acid $577 \mu \mathrm{mol} / \mathrm{L}$ and vitamin $B_{12}$ level was normal. Urea and electrolyte: sodium $131 \mu \mathrm{mol} / \mathrm{L}$, potassium $5 \mathrm{mmol} / \mathrm{L}$, chloride $100 \mu \mathrm{ol} / \mathrm{L}$, bicarbonate 19 $\mu \mathrm{mol} / \mathrm{L}$. There was impaired renal function with serum creatinine level $420 \mu \mathrm{mol} / \mathrm{L}$ (40-120) and blood urea nitrogen $14 \mu \mathrm{mol} / \mathrm{L}$ (3.7-8.3). Calcium level was low $1.72 \mu \mathrm{mol} / \mathrm{L}$ with normal phosphate, high alkaline phosphate $341 \mathrm{U} / \mathrm{L}$ (0-136), albumin $34 \mathrm{~g} / \mathrm{L}$ with normal total bilirubin and transaminases.

Echocardiogram showed features of hypertensive heart disease, moderate pulmonary hypertension with moderate tricuspid regurgitation. Antineutrophil cytoplasmic antibodies (ANCA) were negative. Serum level of immunoglobulin and complements were within normal limits. Arterial blood gas analysis showed oxygen saturation of $98 \%$. Ultrasound abdomen revealed splenomegaly " $27 \mathrm{~cm}$ ". The kidneys measure $9 \mathrm{~cm}$ "right" and $10 \mathrm{~cm}$ "left" with loss of corticomedullary differentiation. There were small bilateral pleural effusions. Bone mar- 
row aspiration and biopsy showed hyper cellular specimen with grade IV fibrosis and depleted iron store. Features were in keeping with (post polycythemia myeloid metaplasia). 24 hours urine collection revealed massive proteinuria of 8 grams. Work up for secondary causes disclosed normal fasting blood sugar with impaired glucose tolerance. HBV, HIV, HCV were negative.

The renal biopsy showed number of Glomeruli, some of them were unfortunately totally sclerosed nonsurprisingly expected with the relatively advanced renal impairment. The rest of the glomeruli showed segmental sclerosis. There is focal and segmental mesangial matrix expansion. Mild interstitial fibrosis is evident. EM revealed segmental sclerosis, the histology was compatable with focal segmental glomerulosclerosis. The patient was treated conservatively.

\section{DISCUSSION}

Few reports of PV with concomitant renal parenchymal disease have been published (13-18) whereas erythrocytosis with accompanying renal disease has been reported more often (8-12) In 1983, Plomley et al reported six patients with polycythemia vera and proteinuria. Half of them showed mesangioproliferative GN, most probably IgA-N. However, the diagnosis was not well established by immunofluorescence (IF) or electron. microscopy (EM) studies. A combination of polycythemia vera and Henoch Schonlein purpura was reported by Kanauchi et al in 1994, where the pathology of renal biopsy revealed crescentic GN with global glomerular sclerosis and deposition of $\lg A$ in the mesangium.

In 1997, Kasuno et al ${ }^{(17)}$ reported two cases with concomitant polycythemia vera and immunoglobulin $-A$ nephropathy (IgA-N) with simultaneous aggravation of proteinurea and erythrocytosis. The renal biopsy of both patients revealed active crescentic GN with mesangial proliferation accompanied by mesangial predominant depositions of IgA. These findings were confirmed by IF and EM. The author speculate that the severe circulatory disturbances in both patients contribute to the progressive course of GN.

In 2002, Chung et al(19) described a 46 year-old patient, presented with heavy proteinurea, chronic renal failure and PV. Renal biopsy of this pa- 
tient with EM \& IF were confirmatory of $\lg A(N)$. The pathogenesis of glomerular disease in PV patients until now is not very clear. Possible mechanism include the thrombotic episodes together with the circulatory disturbances that commonly occur in PV patients, result in Impairment of renal function as well as exacerbation of pre-existing GN.

Recent reports have shown that several cytokinase and growth factors play a role in the progression of GN, such as platelet-derived growth factor and insulin-like growth factor which has been demonstrated in the peripheral blood mononuclear cells from patients with $\operatorname{IgA}-\mathrm{N}$. There is increasing evidence that leukocytes and platelets adhering to the capillary walls of the glomeruli causing direct insult and leading to the development of renal failure, is another possible mechanism. Our case had PV for 10 years, transformed to myelofibrosis, and nephrotic syndrome. Secondary causes of nephrotic syndrome were excluded. Renal biopsy revealed FSGS confirmed by EM. Our case presented with hypertension with increased number of platelets and leukocytes, these factors definitely contributed to the progression of the disease.

The rarity of cases hindered the study of the pathogenesis in depth, however we speculate a casualrelationship between PV and glomerular disease. The circulatorv disturbance and abnormal production of blood cells greatly contributes to the progression of the disease. Prompt and strict treatment of PV in addition to control of the high blood pressure and thrombotic episodes in PV are important factors to prevent or ameliorate glomerular disease.

\section{REFERENCES}

1. Adamson, J.W., Fialkow, P.J., Murphy, S., Prchal, I.F. and Steinmann, L. (1976) : Polycythemia vera: Sem-cell and probable Clonal origin of the disease. New England Journal of Medicine; 295: 913-916.

2. Turk W (1904) : Beitrage Zur Kenntnis des symptomenbildes poly-zythamie mit milztumor und zyanose. Wien Klin Wochensch. 17:153.

3. Modan B (1965) : An epidemiologiMANSOURA MEDICAL JOURNAL 
cal study of polycythemia vera blood 26: 657, 1965; J Chronic Dis. 18:605.

4. Silverstein $\mathrm{M}$ et al : Myeloproliferative disease: Polycythemia.

5. Wasserman LR (1971) : The management of polycythemia vera $\mathrm{Br} J$ Haematol. 21:371.

6. Osler W (1908) : Chronic cyanosis with polycythemia and enlarged spleen; A new clinical entity. AMJMed Sci 126: 187,1903; Lancet 1:143.

7. Najean Y, Rain JD, Dreschc, et al. (1996) : Risk of leukemia, carcinoma, and myelofibrosis in p32 or Chemotherapytreated patients with polycythemia vera: A prospective analysis of 682 cases. Leuk Lymph.; 22 (suppl. 1):111.

8. Sonneborn R, Perez GO, Epstein M, Martelo O, Pardo V (1997) : Erythrocytosis associated with the nephrotic syndrome. Arch Intern Med, 137:10681 072.

\section{Hoppin EC, Depner T, Yamuchi}

Vol. 35, No. 3 \& 4 July., \& Oct, 2004
H, Hopper J Jr (1976) : Erythrocytosis associated with diffuse parenchymal lesions of the kidney. $\mathrm{Br} \mathrm{J}$ Haematol: 32:557-563.

10. Khan IH, Simpson JG, MacLeod AM, Catto GR (1993) : Secondary polycythemia associated with idiopathic membranous nephropathy. Nephron; 64:310311.

11. Chen YC, Yeh JC, Chen HS, Hsu HC (1990) : Secondary polycythemia associated with membranous nephropathy. Clinnephrol; 33:148151.

12. Lim CS, Jung KH, Kim YS, Ahn C, Han JS, Kim S, Lee JS. (2000) : Secondary polycythemia associated with idiopathic membranous nephropathy. Am J Nephrol; 20:344-346.

13. Plomley RF, Sullivan JR, Whitworth JA, Kincaid-Smith PS, Fairley KF. Brown RW (1983) : Polycythemia vera and glomerulonephritis. Aust N Z J Med; 13:125-129. 
14. Kanauchi M., Dohi K., Shiiki H., Fujii Y., Ishikawa H. (1994) : Henoch-Schonlein purpura nephritis associated with polycythemia vera. Intern med; 33 :36-40.

15. Au WY, Chan KW, Lui SL, Lam CCK, Kwong YL. (1999) : Focal segmental glomerulosclerosis and mesangial sclerosis associated with myeloproliferative disorders. Am J Kidney Dis; 34:889893.

16. Sharma RK, Kohli HS, Arora P, Gupta A, Murari M, Pandey R, Kher V, Das BK (1995) : Focal segmental glomerulosclerosis in a patierlt with polycythemia vubra .era. Nephron; 69:361.
17. Kasuno K, Ono T, Katama $T$, Kawamura $T$, Suyama K, Oyama A Matsushima H, Kuwahara T, Muso E, Sasayama S (1997) : IgA nephropathy associated with polycythemia vera: Accelerated course. Nephrol Dial Transplant; 12 : 212-215.

18. Kim MY, Lee CW, Oh JY, Choi JS, Ryu SH, Im JS, Yu DS, Jae YS (1994) : A case report of polycythemia vera associated with IgA nephropathy. Korean J Nephrol; 13:977-981.

19. Jaegul Chung, Pae Gun Park, Kyung-il Song; AMJ Nephrol 2002 : 22 : 397-401. 
